Article

\title{
Preparing for Successful Collaborative Contracts
}

\author{
Ole Jonny Klakegg ${ }^{1, * \mathbb{C}}$, Julien Pollack ${ }^{2}$ and Lynn Crawford ${ }^{2}$ \\ 1 Department of Civil and Environmental Engineering, Norwegian University of Science and Technology, \\ 7491 Trondheim, Norway \\ 2 School of Civil Engineering, The University of Sydney, Darlington, NSW 2006, Australia; \\ julien.pollack@sydney.edu.au (J.P.); lynn.crawford@sydney.edu.au (L.C.) \\ * Correspondence: ole.jonny.klakegg@ntnu.no; Tel.: +47-9173-3461
}

\section{check for}

updates

Citation: Klakegg, O.J.; Pollack, J.; Crawford, L. Preparing for Successful Collaborative Contracts. Sustainability 2021, 13, 289. https://doi.org/ $10.3390 /$ su13010289

Received: 21 October 2020 Accepted: 26 December 2020 Published: 30 December 2020

Publisher's Note: MDPI stays neutral with regard to jurisdictional clai$\mathrm{ms}$ in published maps and institutional affiliations.

Copyright: $\odot 2020$ by the authors. Licensee MDPI, Basel, Switzerland. This article is an open access article distributed under the terms and conditions of the Creative Commons Attribution (CC BY) license (https:// creativecommons.org/licenses/by/ $4.0 /)$.

\begin{abstract}
Preparing well before entering a contract is always vital, independent of the characteristics of the project and type of contract. However, as projects become larger and more complex, and value for stakeholders and society becomes the dominating perspective on success, the need for well-developed collaboration is becoming more and more critical. In this paper, we investigate how the parties should prepare for a collaborative project. The purpose is to help owners secure the success of the project for its key stakeholders. We choose to address the issues as an active risk mitigation strategy that serves as a vehicle to reduce uncertainty, avoid unnecessary risks, and utilize opportunities as a project owner. We look at the project mainly through a project owner perspective, but on key points, we contrast this with contractor perspectives. The research was performed in Australia in 2020 and includes public and private sector investment projects. The methodology is qualitative case studies and includes primarily in-depth interviews supplemented with document studies and two workshop group discussions. The paper highlights the difference between being collaborative in a contract and using a collaborative contract. The results document significant differences in preparations depending on the degree of complexity of the projects. One major difference is illustrated in the different levels of precision in terms and definitions used in communication. Complex projects require freedom of interpretation only gained by allowing wide and less precise expressions.
\end{abstract}

Keywords: construction; complexity; collaboration; contract; project delivery method; risk mitigation strategy; risk allocation; successful project delivery; stakeholder value

\section{Introduction}

The relationship between the contractor [1] and the owner has a major impact on the performance of construction and infrastructure projects. Research has shown how important social relationships are to project performance, including the vital role played by trust [2]. Research has also revealed a generally shared belief amongst practitioners that trust, honest communication, and a shared vision are essential for effective relationships between contractors and owners [3]. In addition, the importance of creating an environment where all parties benefit from the contract has been repeatedly emphasized in the literature (e.g., [4-7]).

\subsection{Limitations of Traditional Approaches to Contracting}

One of the major factors that sets the context for contractor-client relationships in projects is the project contract: the formalized documentation of the expectations and commitments to which both parties intend to adhere. Prescriptive approaches to contracting in construction and infrastructure projects have tended to be the norm in the field [8]. The typical approach to management is based on a competitive procurement process, followed by a focus on surveillance and control during implementation [9]. However, the standard approach of prescriptive, fixed-price, lump-sum contracting is coming under 
increasing criticism. One concern from the client's perspective is that once contract terms have been agreed, there is little incentive for a contractor to do more than what is needed to meet the minimum contractual requirements [10]. This approach has also been criticized as unable to handle the increasing complexity of projects [9]. However, the most common complaint raised in relation to competitive, fixed-price contracts relates to the impact on the relationship between the client and contractors. Fixed-price contracts have been identified as associated with lower trust between parties to a contract, misaligned objectives, poor performance, a confrontational culture at work [10], and an adversarial relationship between the parties [11]. Traditional construction procurement approaches have reinforced the differences between client and contractor goals and values [12].

"Under adversarial relationships, owners are likely to challenge requests for approval, force compliance by withholding funds, and overly control the contractors' works. Meanwhile, contractors might exploit potential claims by aggressively negotiating change orders and withholding vital information. Often, small issues easily escalate into major disputes causing costly delays and ending in formal litigation." [3]

Yang et al. [13] identify that construction and infrastructure are particularly risky businesses. In response to increases in the risk and complexity of projects, and schedule and budget constraints, many are urging for a change in how contracting is managed in construction [10]. Internationally, there is an increasing interest in collaborative business arrangements and collaborative forms of contracting in infrastructure and construction projects; these forms are often referred to as alliancing or partnering [9]. This trend has been found to be particularly true in the era of New Public Management, in which governments and private agents are expected to work together in increasingly complex, sophisticated, or convoluted contractual arrangements $[14,15]$.

\subsection{Collaborative Contracts}

There are a variety of forms of collaborative relationship, including strategic alliances, partnering, relational contracting, and integrated teamwork [3], and there is general acceptance that contract choice should be dependent on factors such as the owner's internal capabilities, expected allocation of risk, and the current market conditions [11]. A range of detailed studies of the differences between collaborative contract types can be found, such as Chan et al.'s [10] study of the differences between Guaranteed Maximum Price contracting and Target Cost Contracting, but irrespective of the specific type of collaborative contract, some common elements persist. While the term "partnering" may be used to refer to long-term contractual relationships and "alliancing" may refer to isolated collaboration on discrete projects, the terms are also used interchangeably [8].

From a contractual perspective, collaborative contracts differ from fixed price, lumpsum contracts, as they attempt to make room for the different institutional logics inherent in the participants [16]. This allows for an opportunity to create a coordinated, but temporary, multi-party organization that shares risks and rewards [17]. Partnering and alliancing generally aim to develop collaborative relationships involving shared trust, joint problem solving, open communication, and communal problem solving [3]. While some approaches to partnering and alliancing may focus on the letter of the contract, other approaches emphasize the principle of changing from an adversarial, short-term perspective to a collaborative, long-term world view [11].

Perspectives on relational contracts have developed significantly over the last few decades. Macneil [18], in his wide-ranging exploration of neoclassical and critical legal studies perspectives on relational contracts, traces aspects of relational thinking back to the 19th century, particularly in the context of property, trust, corporation, and family law. In 2000, Bresnen and Marshall [2] noted that although collaborative forms of contracting and partnering were becoming widespread, there was still little empirical research that investigated their impact, and most of the support for these forms of contracting was based on anecdotal evidence. Their case study research revealed that the use of a partnering 
approach was not without problems but may improve performance due to indirect factors and may reduce the likelihood of litigation.

Later studies (e.g., [19]) help to clarify the field by clearly distinguishing between project partnering, project alliancing, and integrated project delivery. In all three approaches transparent financial arrangements, collaborative multi-party agreements, shared risk, joint decision-making, and early engagement are key components. According to Lahdenperä, project partnering has the longest traceable history of relational project arrangements as a derivative of the strategic partnership. The earliest project partnership was identified as occurring in 1988 in a US Army Corp project with the intention of avoiding construction disputes, and project partnering appeared in UK projects soon afterwards. Project alliances, by contrast, can be traced back to a 1992 British Petroleum contract in the North Sea, involving a contractor risk and gain sharing approach. Integrated project delivery is a more recent concept, emerging in 2003 as a variation to a design and build contract involving multiple complementary enterprises.

Many benefits have been attributed to partnering and alliancing. Partnering principles have been found to improve project delivery efficiency [13]. These principles have been associated with superior project performance [18] and have been found to be the most effective and efficient form for delivering complex public infrastructure projects [16]. Partnering and alliancing have been associated with improved teamwork quality when compared to that found in more traditional contract forms [11] and higher levels of trust [19]. The focus of partnering is on substituting competition with trust and collaboration, which leads to a more balanced relationship [20]. They are considered more collaborative than lump-sum contracts [11]. They contribute to improved risk management [13] and have been associated with promoting sustainable delivery practices [9]. They can improve the speed of change decisions and provide a vehicle for incorporating contractor expertise in the design phase [10]. They have been found to result in greater clarity of understanding of the contract [21], a clearer understanding of client requirements and expectations [13], and general improvements in customer satisfaction [18].

\subsection{Performance in Collaborative Contracts}

However, there are also contradictory results in the literature, suggesting that approaches to collaborative contracting may not always be more effective than lump-sum contracts [3]. The use of a collaborative contract does not directly guarantee a successful project [12,22]. Research by Supraptu et al. [11] and Meng [1] both found no direct links between different contract types and project performance, while Merrow [23] identified that in some cases, alliances may actually underperform lump-sum contracts.

The difference in performance between collaborative and competitive contracting may lie in whether the collaborative form of contracting does actually achieve heightened levels of collaboration. This is not always achieved, as adversarial attitudes are not always avoided through use of a collaborative contract [11]. This has been referred to as the "partnering paradox", in which the heightened performance expected in a collaborative contract is not achieved because of persistent adversarial attitudes [24].

Performance in a collaborative contract appears to be highly dependent upon factors such as the openness of senior management, a no-blame culture, commitment, and trust, with collaborative relationships failing because of a lack of sufficient effort in the early stages in establishing a shared culture, and a lack of senior commitment [11]. Public sector management capability also appears to play a strong role in the success of public-private collaboration [25]. Financial measures in the contract do not appear to be a sufficient tool for ensuring commitment and motivation [2]. It is clear that it is a complex task to first establish, then maintain, a collaborative relationship over a long-term project involving multiple organizations [26].

It is unclear which is the best strategy for ensuring a collaborative attitude between client and contractor [9]. Commercial pressure can present a significant obstacle to the success of a partnering arrangement [27]. It is clear that the duration of a relationship 
affects the success of different procurement methods. As time passes, parties develop an understanding of each other, allowing mutual trust to develop [9,28-30]. However, it is not always possible to wait for this to develop naturally. One way of developing trust in collaboration is through formal mechanisms that provide a way of structuring the relationship, such as through performance incentives and complex selection procedures [8]. Technologies of distrust, such as auditing, have also been found to assist in sustaining collaborative relationships [12]. However, Suprapto et al. [3] argue that current practices may over-emphasize formal mechanisms at the cost of trivializing the social aspects of relationship development. They identified four distinct practitioner perspectives on how to improve collaborative relationships, and it is interesting to note that despite differences in the views, all four practitioner perspectives emphasized the significance of capability, team integration, and relational attitudes.

\subsection{Risk and Complexity}

Managing a collaboration between two or more organizations delivering a large construction or infrastructure project is clearly a complex endeavor. Yang et al. [13] argue that a partnering approach is essential when pursuing international competitive advantage in construction precisely because of the complex relationships involved in such a project. Daniel and Daniel [31] demonstrate that understanding large projects as complex adaptive systems provides an effective framework for understanding project dynamics. However, there is little research that explores the relationship between complexity and contractual forms in construction and infrastructure projects. For example, while Qiu et al. [32] explore causes for institutional complexity in megaprojects, and its impact on governance in a single case study, they do not consider the impact of different contractual relationships.

Research by Matinheikki et al. [16] stands out in this space, investigating institutional complexity in public infrastructure alliances. They note that difficulties faced when delivering public infrastructure projects come from the structural complexity that results from the multi-organizational structure and institutional complexity created by the different worldviews inherent in the organisation. They identify that " ... we lack empirical illustrations and rigorous theorizing of mechanisms for responding to institutional complexity" (p. 298). In their paper, it is argued that the process of establishing an alliance is a process of hybridization, where potentially conflicting organizational logics are superimposed over a newly created alliance organization, which is a process that results in institutional complexity. Their paper provides a detailed examination of how institutional complexity can arise through exploration of a single case, treating complexity, in this case institutional complexity, as something that arises out of the process of creating an alliance. While Matinheikki et al. [16] explore the implications of the complexity created by alliancing, they do not speak to the relationship between complexity and the use of different approaches to contracting, leaving open questions about how different levels of complexity could affect the use of different contract forms.

Daniel and Daniel [31] noted that the "... question of "how dynamic complexity influences megaproject management" is critical", while Bresnen [8] identified that "... there is a dearth of critically informed work that attempts to understand the problems and limitations of partnering in practice." The research presented in this paper seeks to further develop this area of enquiry by pursuing three related research questions:

- How does complexity challenge the use of traditional/transactional contracts?

- How should the actors prepare for a successful contract in a complex situation?

- How can actors improve the basis for stakeholder value during preparations for contract?

The paper is outlined as follows: The introduction presents the significance of the study and outlines relevant literature. The Materials and Methods section explains the research methodology. Then, the results section follows, presenting the interviews and analysis of the materials. Discussions follow where we show how these findings expand our knowledge in the field of study. The conclusion presents answers to the research questions and highlights the implications for research and practice. 


\section{Materials and Methods}

This study is a qualitative, exploratory approach that aims at mapping practices and views held by senior individuals that represent a broad set of perspectives on construction projects. The systematic research process is shown in Figure 1. The ambition was to understand what makes an infrastructure project and collaborative contract successful.

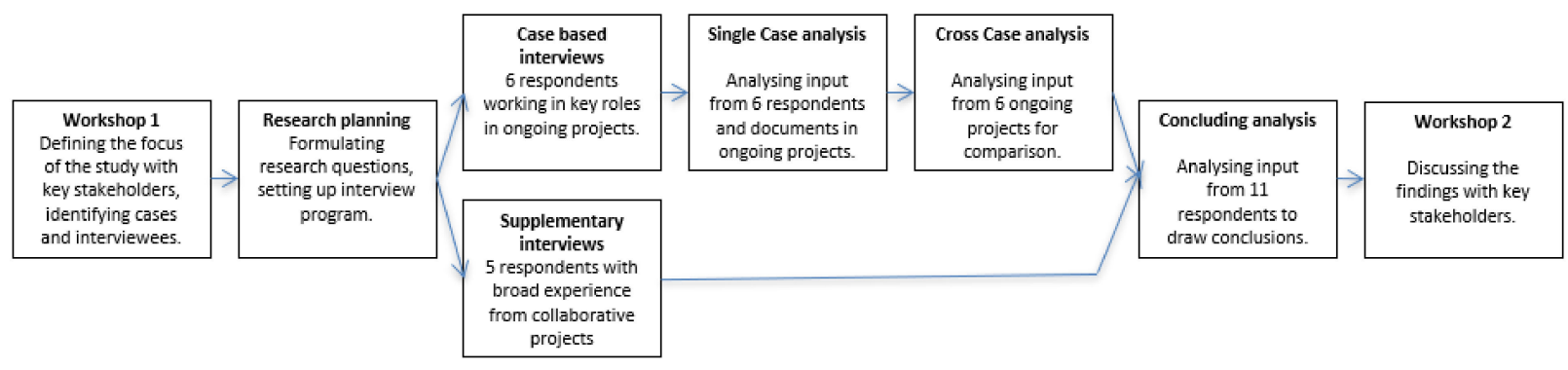

Figure 1. Research methodology—structured approach.

This study started with a roundtable held in Sydney in November 2019. We selected respondents based on two strategies: first, each participating organization recruited 1-2 respondents within their own staff, and secondly, we directly contacted individuals that have or have had key positions related to collaborative projects. Both strategies lead to experienced individuals with relevant knowledge and experience.

Two different types of interviews were performed, although the same questions were asked: One set of interviews were case based. The questions were answered from the perspective of one particular project-a given context. Six single cases were represented in the interviews. Following this, there were supplementary interviews with key individuals with long experience and knowledge of the questions seen from several perspectives and positions. These interviews add nuances and depth to the analysis. There are five such interviews.

This research includes interviews with eleven individuals representing different organizations (except for two individuals that represent the same public organization). All interviewees are senior practitioners with more than 20 years of experience. Seven interviewees operate actively in a role as sponsor or project manager. Three interviewees are experts in facilitating and coaching collaborative projects. One interviewee represents a private contractor.

Each respondent received several documents before the interview: an introduction to the topic, brief information on their rights as contributors to research, and a consent form to be completed, signed, and returned. Those that worked in a project also received an additional note on complexity with a complexity measuring tool that they filled in and returned to the authors.

The tool selected for assessing the level of complexity of the projects was the GAPPS CIFTER [33]. Of the many tools available for measurement of the complexity of projects (e.g., [34-38]) the CIFTER has the advantage of specifically addressing the management complexity of projects, it has been described as "the most researched model" [39], and it is the simplest to complete, having only seven factors against which complexity is assessed. Other instruments have over 50 items requiring completion [35,38,40], making them unwieldy for the purpose of this study. The instrument was developed by practitioners [41] and is therefore couched in terms that have meaning for those involved in project delivery. Research has confirmed a high level of agreement between self-assessed and independent assessor ratings [42].

The interviews had an average length of $70 \mathrm{~min}$. All interviews were taped with consent from the interviewee, transcribed using the digital tool Otter.ai, analyzed individually, and sent back to the interviewee to give them opportunity for comments and confirmation. 
A cross-case analysis systemized the input from the interviews related to each research question. The analysis itself was done manually, with some deductive-but mainly inductive reasoning. A main task in this research was text analysis, structuring and composing the essence of all the fragments offered by the interviewees. To help complete and check the contents of the interviews, a set of theoretical frameworks were used to support the analysis. Relevant framework models are described in the introduction.

\section{Results}

Interviews were made across New South Wales, Victoria, and Western Australia over a period of two months. The case-based interviews covered buildings for the housing, health, and university sectors, as well as road and railway infrastructure projects. The supplementary interviews were of a general nature covering all sectors and project types. Each interview resulted in a specific checklist that described the process of preparing for a collaborative contract. All these checklists were then combined into one generic checklist. This generic version is illustrated in Figure 2.

\section{(0) Organisational maturity \\ Establish: \\ - ambition to collaborate \\ - culture for openness and sharing \\ Develop Execution strategy \\ Check resources and other preconditions \\ to start \\ Decision: Start tender process}

\section{CLARIFICATIONS}

- Involve with stakeholders

- Develop trust with candidates

- Perform interview process

- Check out common understanding

- Educate if needed

Decision

Initiate tender step 2

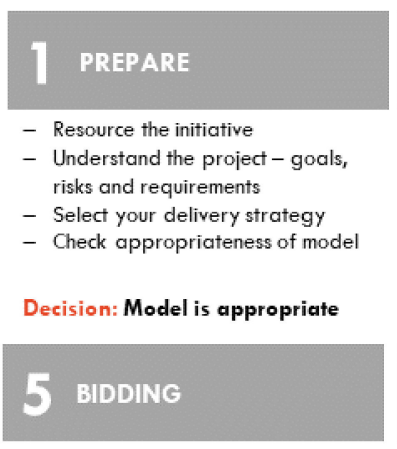

\section{- Invite bids from shortlist \\ - Receive and evaluate bid \\ - Evaluate solutions and total cost is a systematic way}

- Select winner

\section{Decision:}

Final decision on winner

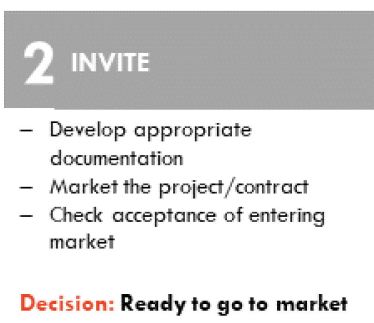

\section{JOINT DEVELOPMENT}

- Involve face to face

- Appoint facilitator

- Partnering workshops

- Involve in planning together

- Consider management and

structural consequences

- Continuous evaluating

Decision:

Goals and strategies approved

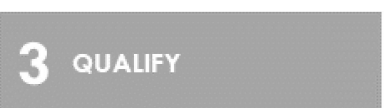

- Invite/announce RFI/RFQ

- Receive and evaluate info

- Run selection workshops

- Select candidates

- Check acceptance of shortlist

Decision: Shortlist is accepted

\section{FORMALISE CONTRACT}

- Set up the formal contract document

- Negotiate remaining details

- Finalise resources

- Plan for mobilisation

- Check acceptance

Decision:

Accept final contract and sign it

Figure 2. Generic checklist based on 11 interviews.

Six of the interviews represented the preparations in real-life projects in specific contexts. These checklists are of particular interest in the analysis in this article. There were several differences between individual checklists mirroring the different types of projects, situations, organizations, and goals defined for each project. This was as expected. There were also many similarities, illustrating that across all types of projects and situations, the pre-contract process comes down to the communication and clarifications between the people involved. The structure given by the eight steps in Figure 2 defines a common multiple of all interviews in this study. One of the given qualities of this checklist is meeting the formal requirements given in procurement regulations for public sector.

Given that we try to identify consequences rooted in aspects of complexity, it was crucial to have some sort of assessment of the degree of complexity for each of these cases. Complexity was self-assessed by the respondents using the CIFTER framework developed by GAPPS [33]. The CIFTER forms part of a framework for performance-based competency standards for two levels of project managers: Level 1 for "normal" projects and Level 2 for complex projects. The framework is intended to be used to assess threshold competencydemonstration of the ability to do something at a standard considered acceptable in the workplace. In this study, we use the tool, not to assess the competency requirements, but rather the perceived degree of complexity in the situation in which the project manager is working. Figure 3 shows the level of complexity across all case projects. In the CIFTER framework, a score below 11 signifies a simple project, a score of 11-18 is moderately 
complex, and above 19 is highly complex. In this paper, an additional category was added to signify two extremely complex projects, with scores of 24 or above. None of the cases analyzed in this study were classified as simple. The projects were classified as moderately, highly, or extremely complex. In this research, we explored whether there was a difference in the way the interviewees prepared for collaborative contracts, levels of complexity, and why these differences occur.

\begin{tabular}{l} 
CIFTER - Project Management Complexity Factor \\
Stability of context \\
Number of disciplines, methods, or approaches \\
Magnitude of implications \\
Expected financial impact \\
Strategic importance \\
Stakeholder cohesion \\
Number and variety of interfaces \\
\hline CIFTER - Project Management Complexity Factor \\
\hline Stability of context \\
Number of disciplines, methods, or approaches \\
Magnitude of implications \\
Expected financial impact \\
Strategic importance \\
Stakeholder cohesion \\
Number and variety of interfaces \\
\hline CIFTER - Project Management Complexity Factor \\
\hline Stability of context \\
Number of disciplines, methods, or approaches \\
Magnitude of implications \\
Expected financial impact \\
Strategic importance \\
Stakeholder cohesion \\
Number and variety of interfaces \\
\hline
\end{tabular}

\begin{tabular}{|c|c|c|c|}
\hline 4 & & & 18 \\
\hline \multicolumn{4}{|c|}{ Descriptor and Point } \\
\hline (1) & (2) & (3) & (4) \\
\hline (1) & (2) & (3) & (4) \\
\hline (1) & (2) & (3) & [4] \\
\hline (1) & (2) & (3) & (4) \\
\hline (1) & (2) & (3) & (4) \\
\hline (1) & (2) & (3) & (4) \\
\hline (1) & (2) & (3) & (4) \\
\hline 2 & & & 19 \\
\hline \multicolumn{4}{|c|}{ Descriptor and point } \\
\hline (1) & (2) & (3) & (4) \\
\hline (1) & (2) & (3) & (4) \\
\hline (1) & (2) & (3) & (4) \\
\hline (1) & (2) & (3) & (4) \\
\hline (1) & (2) & (3) & (4) \\
\hline [1] & (2) & (3) & (4) \\
\hline (1) & (2) & (3) & (4) \\
\hline 1 & & & 24 \\
\hline \multicolumn{4}{|c|}{ Descriptor and point } \\
\hline (1) & (2) & (3) & (4) \\
\hline (1) & (2) & (3) & (4) \\
\hline (1) & (2) & (3) & (4) \\
\hline (1) & (2) & (3) & (4) \\
\hline (1) & (2) & (3) & (4) \\
\hline (1) & (2) & (3) & (4) \\
\hline (1) & (2) & (3) & (4) \\
\hline
\end{tabular}

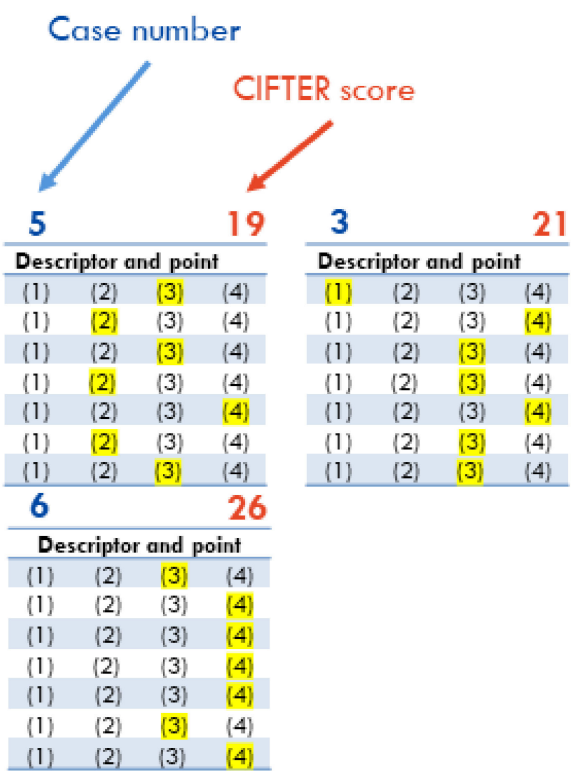

Figure 3. CIFTER score for six cases grouped by level of complexity.

The six case projects show a wide array of different situational characteristics, as is illustrated by the yellow markings of respondents' assessment. For example, most of the projects are operating in a stable context-except the extremely complex ones. Almost all projects have a high number of disciplines, magnitude of implications, and strategic importance. The expected financial impact varies considerably and seems to mirror the size of the projects. Perhaps the two most interesting factors for this study are the stakeholder cohesion and number and variety of interfaces. There is variation in this sample, but the number of and variety of interfaces seem to follow the level of complexity. Stakeholder cohesion is the most interesting characteristic of case 1-the smallest in financial terms but still extremely complex.

\subsection{The Difference Between Being Collaborative in a Contract and Using a Collaborative Contract}

We started this research with the assumption that collaboration is wanted and necessary to deliver successful projects. The literature referred in the introduction confirmed this. The interviews pointed to the same but nuanced the premise on one point: There is a distinction between being collaborative in a contract and using a collaborative contract. This may be explained by referring to Walker and Lloyd-Walker [17], as shown in Figure 25 on page 108 .

First- and second-order collaboration represents traditional and transaction-based models. These build on contracts that are not classified as collaborative but as competition driven. Third- and fourth-order collaboration represents models that are more relationbased, and contracts are classified as collaborative. This does not imply that there is no room for or will to be collaborative in a traditional contract. On the contrary, all the case-based interviews made in New South Wales represent the use of traditional contract forms with an explicit ambition and wish to be collaborative. These indications are also 
evident in the NSW Government Action Plan [43] whereby the Government's Construction Leadership Group (CLG) and its member agencies commit to work together to "procure and manage projects in a more collaborative way" (p. 3).

Interviews conducted in this research also include cases and general experience from explicitly collaborative models including program alliances (Western Australia and Victoria). In other words, both interpretations, "collaborative in a contract" and "in a collaborative contract" are included in this research. Both are valid positions and share the awareness that collaboration is a key to success.

\subsection{The Effect of Complexity on the Process}

Even though there are moderate differences in the level of complexity within the case projects, the results show striking differences. The contrast between case 4 (the least complex) and case 6 (the most complex) illustrates perhaps the most important consequence of the complexity. The authors compared the way preparations were done before a contract is formalized in these two projects. At the stage where the client identified and checked out potential partners and concluded with a shortlist of possible contractors, the work has a different character:

In the project with the lowest degree of complexity, the process had a distinct characteristic of gathering and structuring information. This goes both ways in sequence; information from the client to potential bidders, and the requested information from competing bidders. Dialogue is kept to a minimum. The process had some resemblance to "going by the textbook", even though this project had a rather high degree of complexity. In the project with the highest degree of complexity, the process had a very strong characteristic of iterative process in which the client develops a framework for collaboration in dialogue with the bidders. The process was less structured and harder to overlook.

Going further into detail, the analysis revealed that in the project with the lowest level of complexity, there was a particularly strong focus on checks and balances, formal routines, and gateways. The process had a strong focus on analytical tasks and structured planning activities. In the projects classified as having a medium to high level of complexity, the focus was on checking the potential partner's experience and understanding. The focus was on the selection of partners that could be aligned with the client's objectives, and then the parties developed these further together until the parties reached a level of common understanding that was adequate for signing the formal agreement. In projects classified as having a very high level of complexity, the focus was on developing the project together with potential contractors. Obviously, some necessary planning was done up front to make shortlisting of candidates possible, but the real development happened after the best partner has been identified and selected.

All interviews resulted in a separate checklist for preparations to enter contract. An additional meta-analysis of the resulting checklists from the interviews in projects with different levels of complexity is shown in Figure 4. Here, the checklists for three steps toward signing a collaborative contract are compared. The steps are (1) Shortlisting of candidates, (2) Selection of winner, and (3) Formalizing the contract. Note the tendency to have fewer, but bigger, issues on the checklist as complexity increases.

In the context of a project assessed as very complex, the collaboration must be very open and dynamic. The basis consists of major issues described by less precise definitions and specifications. This keeps open a wide room for improvement and innovation but also requires a high degree of integration to succeed. These processes are to a large degree experiments where practice must emerge as development unfolds. 


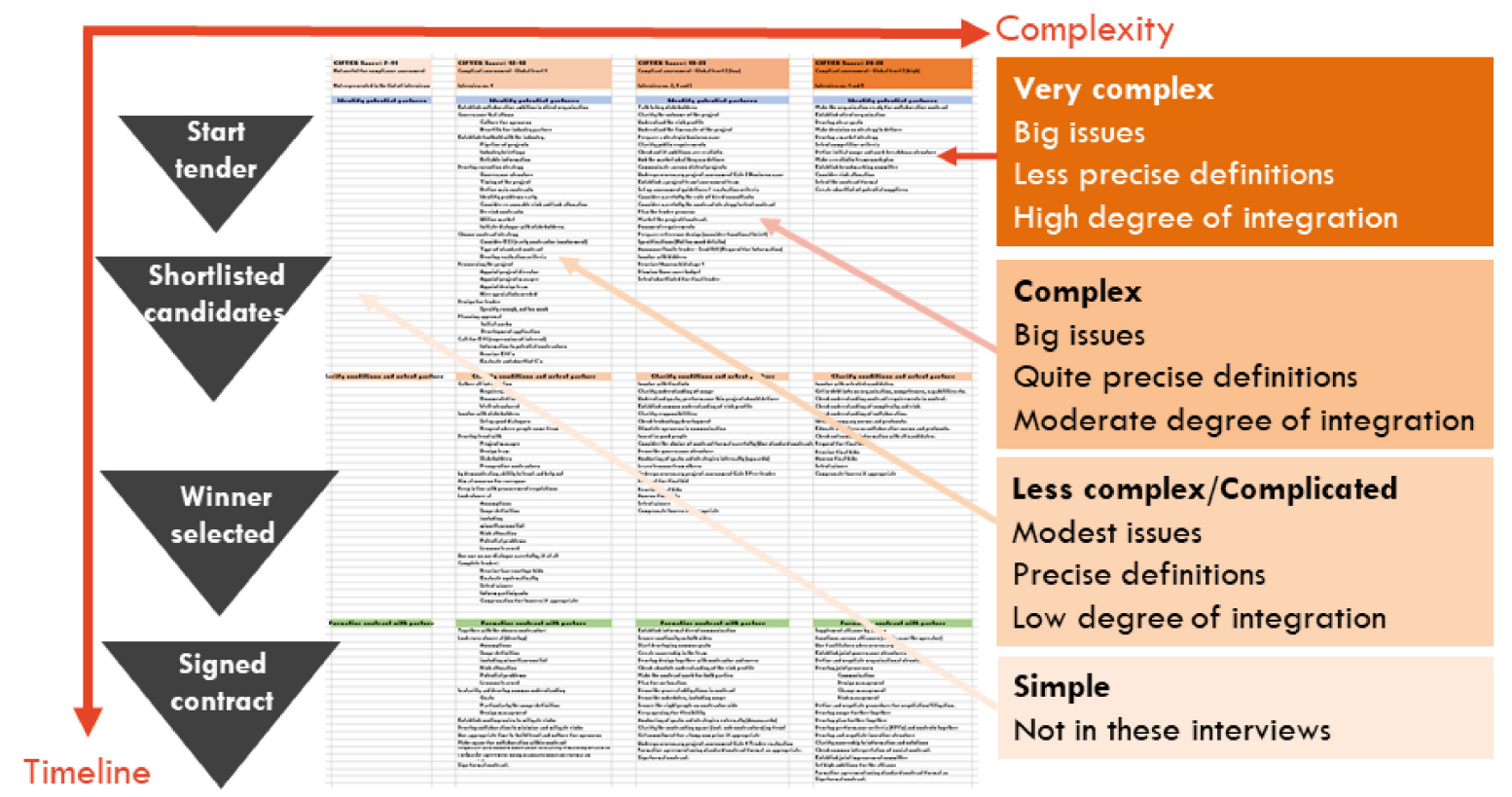

Figure 4. The accumulated effect of complexity on the process from start to formalizing of contract.

For a project assessed as complex, the situation is generally similar, but it is possible to achieve more precision up front in definitions and specifications. If that possibility is used, then the room for innovation is reduced and the need for integration is reduced, too. However, there is no doubt left among the interviewees in this study that openness and close collaboration through all steps are necessary regardless of whether the project is complex or very complex. These complex projects develop their own frameworks and practice guidelines.

In situations assessed as less complex, the big issues are already clarified up front, and those moderate issues that remain are well understood. This makes it possible to define the scope and requirements clearly. Such clarity makes it possible to use delivery strategies that include allocating risk and payment in some detail up front. This makes traditional contracts and delivery models more appropriate, and the level of integration may be kept low. Execution may follow best practice guidelines.

\subsection{Fundamental Roles, Risks, and Opportunities}

The fundamental positions or perspectives may be defined as being owner (client), user, contractor (supplier), and wider society [44]. All these groups of stakeholders may be divided into detailed classifications, but that is not needed for this analysis. When we look at the success of projects, all these fundamental positions must be considered, but in a contract, the positions as client and contractor are the only ones involved.

Interviews show that in the tendering process, the different positions of clients and contractors must be understood and respected. They come from different places and have different stakes in the process. One example is that information does not mean the same thing seen from the two positions. What the client needs to communicate is that "this is an attractive project and an opportunity the contractors should go for" (Interviewee 3). Clients want tough competition to secure lower prices in the bidding process.

What the contractor needs to hear is what shall be delivered and where the challenges and obstacles are hidden. They need this understanding to give the right price offer in the bidding. On the face of it, this may be read as a conflict of interest. "Provide for us to assess and price, and to base our proposal around, the drivers that you're facing and if the challenges and hurdles you're facing aren't clearly identified and truthful, then it is very hard to progress with a good relationship and feel like you're part of a team." (Interviewee 11). The interviewees that mentioned this issue highlighted that in reality, 
there is a common interest in understanding the exposure to risks and challenges so that the right assumptions are made about the future project. All other alternatives will cost more during the process if not identified up front.

Taking the bigger picture into consideration, the collaboration will not be truly successful unless it produces stakeholder value [45]. The stakeholders that are not directly involved in the contract are the ones that hold the key to understanding values represented by relevance and sustainability [46]. If the solution developed and delivered by the project is not in line with the users' needs and priorities, the client's investment will fail, and there is no reconciliation in that the contractor might have made money in the process.

Given the emphasis on this in the literature, it was rather surprising to establish that a broader stakeholder perspective was hardly mentioned by the interviewees. Even if the setting specifically focused the contract on areas other than stakeholder value, the interview questions were in the context of success, and it was surprising that this context did not lead interviewees to discuss other key stakeholders. Only one of the interviewees put the user as the center of attention, as shown in Figure 5.

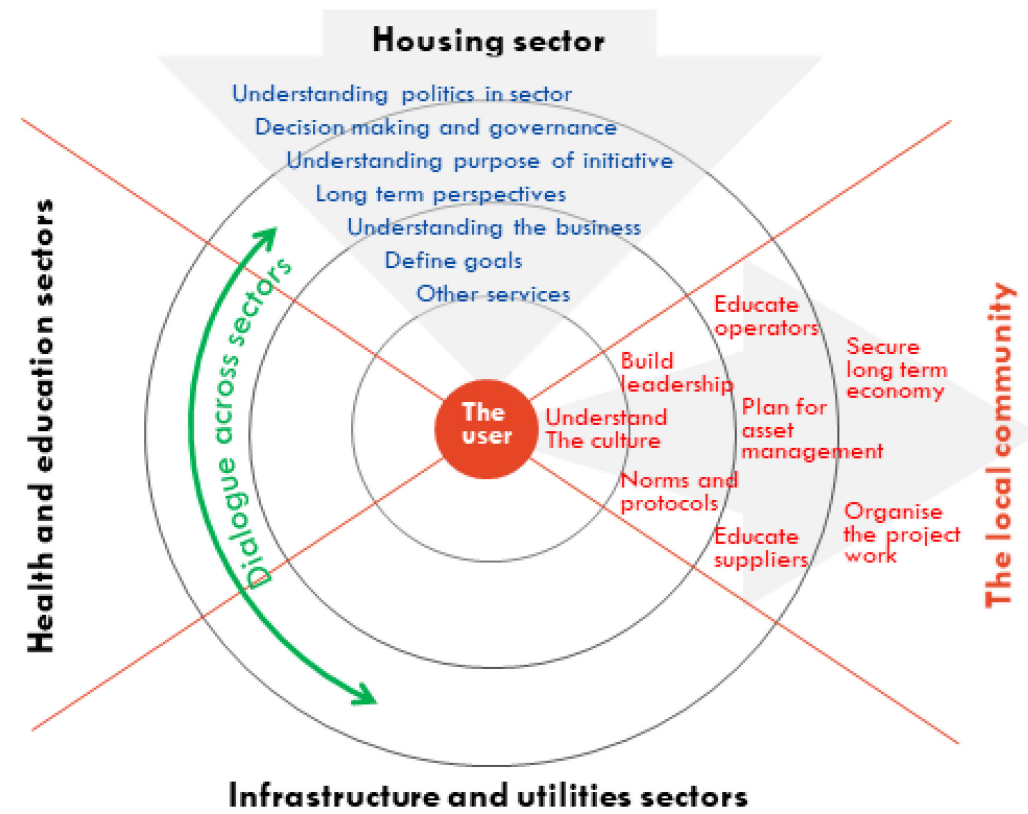

Figure 5. Visual summary of interview from case number 1.

It is worthwhile exploring this case in more depth, as it illustrates a perspective that was not found in the other cases. This interview described an extremely complex case involving a geographically distributed program of smaller projects. The visual summary in Figure 5 is multidimensional. Circles may indicate levels of government (or not). The primary message is: Put the user at the center of attention. This is supported in theory by the acknowledgement that success depends on the ability to create value for stakeholders. Here, the user is the key stakeholder, the one stakeholder that the initiative exists for.

Three secondary messages are also indicated in the visual summary:

1. Blue message (arrow top down to center): You need to understand the politics of your own sector and the corresponding governance and decision making. It also implies there is a need to understand business in the host sector and think long term. This points to:

2. Red message (arrow from center horizontally to the right): You need to work with the users and local community in order to secure long-term value. Sustainability is measured in environmental, social, and economic terms and the project will not be a success unless all three aspects of sustainability are taken care of. This includes building competences and developing long-term asset management, which points to: 
3. Green message (circular arrow on left hand side): The solution depends on what happens in other sectors, too. Thus, it is necessary to keep an open dialogue across all relevant sectors to make sure experience is exchanged, assumptions are consistent, and resources are well utilized across sectors. This tells us: Collaborative practice depends on breaking with the silo-thinking tradition.

There was little evidence in the interview transcripts or meta-analysis of the process to indicate that there was a significant focus on users and society, except in one interview. Interviews in this study show a high level of focus on strategic perspectives and major decisions along the timeline from start to when the formal agreement is signed. The owners' perspective dominates at the start and at the end of this time sequence, as key decisions are identified. The supplier perspective (contractor's position) is a main focus of all interviews. This is no surprise, given that all the respondents from case-projects are active sponsors or project managers. This represents key issues concerning their own responsibility and expertise.

Consideration of the users' perspective was surprisingly missing during the majority of the interviews. Analysis of the interviews identified only a few items representing the users' perspective. This is surprising, as it is the use of what is developed and delivered by the project that represents the purpose of the project. Benefits such as potential for income, return on investment, or simply solving the problem at hand lies in the users' perspective but it received little attention. Only two interviewees explicitly talked about users. Similarly, there is little focus on the public perspective once the project has started. At the start of the project, the public perspective was in focus as a check of external preconditions at the outset. This may be noted as a strong argument for having a gateway process with checks and balances on behalf of society. However, this was only mentioned by one interviewee.

\section{Discussion}

Projects are fundamentally about creating value for stakeholders. In this context, contracts are fundamentally about regulating the relationship between two or more parties that choose to collaborate in that project in order to maximize that value. The contract defines the rules of the game and may significantly influence planning, engineering, and production processes. Some might say that the obvious thing to do in preparing for entering such a contract is to hedge your own position, securing your share of the output without investing more than you have to.

Economic theory informs us that the more competition, the lower the unit price and more advantageous bids [47]. Game theory will set this up as potential for winning or losing, depending on how you play. Contract theory will tell you it is a matter of identifying risks upfront and allocating them to the party that is best positioned to manage them [48]. This will minimize the risk premium and thus give the lowest total cost for the client. These theories have formed the basis for best practice projects over decades. However, this has not made projects particularly successful [49]. Actors that do not see beyond short-term business are not preparing for a successful project [50], unless perhaps when the project is not particularly complex. As Snowden and Boone [51] told us: in a simple situation, the leader may identify and categorize the issues and choose the response prescribed in guidelines. They also gave us an understanding of what is needed to handle the complexity, probe, sense, and respond. It is about recognizing emerging patterns and responding to them, not about pre-identifying order.

\subsection{Complexity and the Selection of Contract Type}

An effect of complexity is that the process becomes unclear, unpredictable, and unmanageable. Assumptions are diffuse, responses are unknown, solutions are debatable, and everything is more uncertain. The parties involved need more competence, flexibility, and resilience to play this kind of game. The process becomes emergent; it cannot be described in detail upfront. Consequently, the parties involved become more dependent 
on each other, they need to iterate to find optimal solutions and processes that enable them to make decisions and manage design and production.

Transactional contracts are built on the assumption of predefined order. In a simple situation, the client knows what he wants to buy, how to specify it, who can deliver it, and what a reasonable price is. Everything you need to identify and describe upfront can be handled in a structured way. The supplier knows exactly what is wanted and how to deliver it. Strong competition on the supplier side will push the suppliers to be productive and offer the delivery at a competitive price. In such situations, there is no reason to look for other forms of contracts.

Often, the situation is more complex than this. From the position of working in a less complex situation with transactional contracts, the first step toward handling complexity is to act collaboratively in contract. In more complex situations, the assumption of predefined order is no longer valid, but the contracts may still be open for some flexibility to handle the emergence.

There must be room for collaborative behavior to accommodate complexity and/or uncertainty. How this flexibility is used is a leadership matter. In a situation with a significant degree of complexity, transactional leadership makes the game into a win-lose or even a lose-lose game. When the need for upfront identification and allocation of risks results in suboptimal contracts, it will lead to imbalance between the parties and potentially to loss and conflict. If there is no way of identifying upfront the critical issues, there is no way to assess and allocate the risks and rewards up front, either. Bids will not be correctly priced, and decisions are made on the wrong basis. The way this will develop is highly predictable.

\subsection{Complexity and the Room for Flexibility}

When there is insufficient room in the transactional contract for collaborative behavior to handle the complexity, using a collaborative contract may be the best option. These contracts start with the awareness that there is need for dialogue and integration between the parties. This helps them to manage the consequences of complexity-to identify and understand the developing patterns. Developing a collaborative contract involves setting up a framework for collaboration that can accommodate the dynamics and emerging nature of the process and stimulate the collaboration by building trust. Good leadership will potentially be able to turn this into a win-win situation.

At what level of complexity does the situation shift from allowing for collaboration in (transactional) contracts to requiring collaborative contracts? The data from this study are insufficient to give a good answer to this question, but the outcome of the interviews presents a remarkably clear message. The six cases in this study are all complex, as shown in Figure 3. However, even though they are all public sector projects, developing physical infrastructure, and are delivered in Australia by professional project owners, they show significant differences on several complexity dimensions. The analysis in Figure 4 shows distinctly different results despite relatively small differences in levels of complexity. The category with the lowest CIFTER score has an average score of 18, while the next category has an average level of 20, and the highest category has an average score of 25. How can this be explained?

The important difference between the two lowest categories is not only the value itself but where this difference comes from. Figure 3 shows it is in the assessment of either the stability of context (case 4 vs. case 5) or a combination of factors that comes out slightly higher (case 4 vs. case 2 and 3). The middle category includes three projects with quite different characteristics in terms of complexity factors. This complicates the comparison. Comparing the lowest category with the highest category, the difference is more significant and points out stability in context in combination with stakeholder cohesion when comparing case 4 against case 1 . In addition, the financial impact in case 6 is a lot bigger in financial terms than any of the other cases. So, what can be seen when 
comparing the checklist that sums up the preparations for entering a collaborative contract for the three categories?

In the case with the lowest CIFTER score (case no. 4), the process can be described as collecting and structuring known information. Every item on the list is well defined and the terms to describe them are precise. The process described in the interview included little dialogue between the contract parties (client and supplier) before the contract was signed, representing a low degree of integration. This does not mean there was little dialogue between the client and other stakeholders such as users and operators prior to the preparation of the contract. On the contrary, these were included in preparations through detailed discussion on requirements and premises for the process, which in this case included developing a new building amid an ongoing operation.

In the cases with the higher CIFTER score (case nos. 2,3, and 5), the process included more dialogue leading up to the contract being formalized. In these cases, the focus of the dialogue included users and operator's requirements and expectations, as well as regulating authorities and the wider context. In addition, there was significant dialogue with potential suppliers leading up to the shortlisting and choice of contract partner. This was followed by a moderate level of integration between the parties in the period leading up to the formal contract. Another characteristic observed is that the definitions and descriptions were partly less precise, leaving more room for adaptation later. Still, the total impression of the process was one of trying to identify and allocate all relevant risks upfront. One particular observation is that the two cases no. 2 and 3 were similar in nature and owned by the same public project owner. They went through similar processes and used similar contracts. Still, they had slightly different complexity characteristics. Case number 3 had challenges with stakeholder cohesion and was considered a failure in terms of the collaborative process, whereas number 2 was a success.

In the cases with the highest CIFTER scores (case no. 1 and 6), the process included a high degree of dialogue and integration between client and supplier even before the formalization of the contract. In these processes, it seemed to be intentional that the descriptions were left as diffuse descriptions rather than precise descriptions, the focus being on understanding and describing goals and measurement methods to assess the degree of success rather than identifying and allocating specific risks. The process can be described as developing a common framework within which effective collaboration can be generated and matured. Thus, it was also logical to leave lots of room to maneuver within the formalized contract. The upcoming development was simply not very well known at the outset, and in both cases, the interviewees talked about significant changes and additions later (during the contracted works) that were handled within these framework contracts.

\subsection{Setting Up for Successful Collaboration}

The industry and size of the project seems not to represent any relevant signal about the nature of the process. All of the projects involved some aspect of construction, and in the sample, examples of infrastructure projects were classified as both highly and extremely complex. The two cases with the highest CIFTER score were the smallest and the biggest in financial terms. However, looking beyond industry of project, it is worth considering that although all of these cases were referred to by the interviewees as a "project", perhaps "project" is not the best term for some of these activities. The smallest case in financial terms could also have been described as a complex program of many small building projects in a highly complex context with a long-term perspective and particular social implications. The biggest case had a completely different scale in terms of financial impact but could also have been thought of more as a complex program than a complex project, being conducted in a complex environment and with long-term social, environmental, and economic implications.

The type of contract that the parties intend to enter has a significant importance for these processes. Cases number 1, 2, 3, and 4 used a traditional contract based on transactional logic but with an ambition to be collaborative within the limits of such 
contract. Case number 5 is a Public-Private Partnership (PPP) contract. PPP contracts are based on traditional logic but include a wider range of scope elements than typical delivery projects. This introduces the opportunity to include more aspects of collaboration and a more long-term perspective to the process. Case number 6 is a program alliance. This is the only "pure" collaborative contract in this study. Here, the whole logic is based on creating a sustainable environment for collaboration over the long-term and with a scope that emerges and develops as the process unfolds. Obviously, this study has too few cases to draw wide-ranging conclusions.

This analysis points toward one key to successful projects, especially in complex cases: leaving out the user and society perspectives poses a very strong risk to the projects' success. The opportunities that represent increased stakeholder value and thus ultimate success and sustainability for the project are found in these perspectives. Interviews exposed that these perspectives are given little attention in the preparations, even for collaborative contracts. This results in a rather critical analysis.

On the surface of it, there seems to be significant weaknesses in the basic logic from identifying needs in the beginning, developing this into a solution, planning for benefits realization through to securing the intended effect from use of the result. Clients and contractors that are short-sighted and narrow in their assessment of value and preparations for contract will risk focusing on the wrong things and end up with the wrong solution and a failed project, even when the process is well played and the contract fulfilled perfectly.

However, the interviews did not explicitly expose the whole truth. Many of the userfocused issues are present when interviewees mention objectives, requirements, specifications, and scope. However, they are only implicitly present in these interviews. Obviously, the interviewees would have talked more about these issues if asked directly about them. On the other hand, they were not asked to focus any of the other perspectives, either.

The resulting impression is probably very close to what the real focus is in these processes. The parties involved in preparations for contracts are closest to their own perspectives, even in collaborative contracts. There is a danger that the core logic-embedded in the users' perspective-is left to someone else (delegated to designers and consultants perhaps) or lost in the dominating focus on productivity (suppliers' perspective) and economic/financial focus of the owner/investor perspective.

\section{Conclusions}

\subsection{Answers to Research Questions}

The research questions addressed in this study can be answered from the results of the interviews:

- How does complexity challenge the use of traditional/transactional contracts?

Complexity makes it impossible to identify and allocate all risks up front. Thus, the very foundation for the transactional contracts are challenged. In situations with a low degree of complexity, the transactional logic may still produce good results. The power of competition in keeping cost down should not be underestimated. This study clearly indicates that the power of collaboration in handling the complexity is needed when the degree of complexity gets high. As shown in this study, there is a measurable limit to the degree of complexity (measured by CIFTER score) where the transactional logic meets some sort of limit. The level that seems to mark this limit is a CIFTER score of about 20-21.

- How should the owners prepare for a successful contract in a complex situation?

Based on the checklists that resulted from the interviews (see Figure 2), before starting the procurement process, the owner must establish a basis for actually working in a collaborative way. Without it, any attempt will be futile. The execution strategy for the proposed project must be in place and resources and other preconditions to start. The preparation stage is about making the project attractive, but at the same time ensuring the bidders are able to give realistic price bids. The degree of precision and detail in the information at this stage mirrors the level of complexity-understanding this, and its implications, 
is important for all stakeholders. In complex situations, the initial screening for partners is not a question of finding the bidder with the lowest price but rather the bidders that are able to align with the owner's goals and ambitions. The best fitted potential partners are shortlisted and invited to deliver initial bids. Depending on the level of complexity, there has to be a phase of dialogue between the client and bidders to establish that the mutual understanding and realistic expectations are established. This becomes distinctly more important when complexity rises. After receiving and evaluating the final bids, the winner is invited to further develop the more detailed plans and conceptual solutions together before finalizing the formal contract. This period is characterized by a high degree of integration between the client and the supplier in very complex cases. The process uses language and definitions that maintain a significant room open for interpretation and handling emerging aspects in the following process of design, production, and delivery. In short-the preparation for a collaborative contract in a highly complex situation is more similar to developing a framework for managing the process together than an upfront identification and allocation of risks between the parties. Complex projects require freedom of interpretation only gained by allowing wide and less precise expressions.

- How to improve the basis for stakeholder value during preparations for contract?

The major issue in securing stakeholder value is to make sure the stakeholders are involved and taken into consideration at the right stages of development. What this study documents is that the parties involved in preparations for a contract focus on their own and the specific partners' positions explicitly, but for a large part, they leave other stakeholders out or only implicitly include them in developing objectives, requirements, and specifications. We believe a more explicit strategy toward stakeholders is purposeful in the front-end of projects and even necessary when the complexity is extremely high. This will help keep focus on the most important issues that represent opportunities and risks related to stakeholder value.

\subsection{Limitations, Generalization of This Analysis, and Future Research}

All cases in this study are found in Australia and are not representative for all sorts and sizes of projects. However, the issues discussed here are highly relevant to public and private sector projects all over the globe. There is reason to believe these findings are fairly representative for medium to large, complex projects in industrialized countries. Although not to be taken literally in every single case, the principles and tendencies shown here are considered generalizable.

There are several limitations to this analysis, since this research was done without any form of financing or external resources over a short span of time. First, the number of cases is too limited to lead to generalizable findings. Second, there was only one key individual interviewed per case, and thus, there is potentially a high degree of subjective opinion in these sources. Third, the CIFTER-scoring was done as a self-assessment and thus may not be consistent across cases. The differences are small, so this may be a source of error that puts cases in the wrong category. However, the differences in CIFTER score are well tuned in to the differences observed in resulting checklists in Figure 4.

All interviews were transcribed and returned for control by the source with no or very small changes as result. However, a potential cause of error is the influence of each informant's communication style and level in structure when describing their preparations.

Future research may strengthen or challenge the findings of this study by posing similar questions to a larger population of cases in other countries. All interview guides are available, and all interviews are well documented enabling duplication of this study, to determine whether similar patterns emerge in other parts of the world. However, that would not be enough. It is important to make sure the understanding of the causalities is developed further. Triangulation, using other research methodologies and types of analysis would offer potential for greater insight. 


\subsection{Contribution to Research and Practice}

The findings illustrate and support tendencies that are reported in previous literature, clarifying differences that can be identified and the reasons behind them. The results seem to offer a reasonably precise and robust set of explanations of the effect of complexity.

There are insights from this research that can readily be applied in practice. The generic checklist provided in Figure 2 can be used as a guide and as the basis for a more detailed checklist that would apply to preparation for collaborative contracts in specific contexts. The CIFTER was found to be an easily used tool for assessment of a level of complexity that has face validity with practitioners. Figure 4 provides a useful summary of key differences that come into play at different levels of complexity. At lower levels of complexity, there tends to be more focus on clear definitions, process, routines, and gateways, and collaboration may occur within traditional contracts. At higher levels of complexity, the process becomes more iterative, less transactional, requiring mutual understanding. There tends to be higher tolerance for ambiguity, more conversation and opportunity for co-creation, and under these conditions, there is a greater need for specifically collaborative contracts that allow sufficient flexibility to accommodate experimentation, innovation, and emergent practice.

To enable the delivery of sustainable stakeholder value, there is evidence of the need for consideration and focus on users throughout the process, rather than just at the start when identifying requirements. When preparing for collaboration within contracts, or for collaborative contracts, the client and contractor perspectives appear dominant, and there is potential for a more sustainable delivery of value to all stakeholders if other perspectives such as those of the user are given greater and more sustained attention.

Author Contributions: The main author, O.J.K., accounted for the conceptualization, methodology, investigation, formal analysis, writing of original draft preparation, and visualization. The second author, J.P. wrote the original theory part and contributed to the validation, review, and editing of the manuscript. L.C. contributed to the writing, review, editing, validation, as well as supervision of the process. All authors have read and agreed to the published version of the manuscript.

Funding: This research received no external funding.

Institutional Review Board Statement: The study was conducted according to the guidelines of the Declaration of Helsinki, and approved by the Human Research Ethics Committee of University of Sydney (ABN 15211513 464, 20160420).

Informed Consent Statement: Informed consent was obtained from all subjects involved in the study.

Data Availability Statement: Restrictions apply to the availability of these data. Data was obtained from interviewees and are available from the authors with the permission of interviewees.

Acknowledgments: The authors wish to acknowledge the support from roundtable participants and interviewees that contributed to this study. Their time and effort to share experience is greatly appreciated.

Conflicts of Interest: The authors declare no conflict of interest.

\section{References}

1. Meng, X. The effect of relationship management on project performance in construction. Int. J. Proj. Manag. 2012, 30, 188-198. [CrossRef]

2. Bresnen, M.; Marshall, N. The engineering or evolution of co-operation? A tale of two partnering projects. Int. J. Proj. Manag. 2002, 20, 497-505. [CrossRef]

3. Suprapto, M.; Bakker, H.L.M.; Mooi, H.G.; Moree, W. Sorting out the essence of owner-contractor collaboration in capital project delivery. Int. J. Proj. Manag. 2015, 33, 664-683. [CrossRef]

4. Tezel, A.; Koskela, L.; Aziz, Z. Current condition and future directions for lean construction in highways projects: A small and medium-sized enterprises (SMEs) perspective. Int. J. Proj. Manag. 2018, 36, 267-286. [CrossRef]

5. Meng, X. Assessment framework for construction supply chain relationships: Development and evaluation. Int. J. Proj. Manag. 2010, 28, 695-707. [CrossRef]

6. Segerstedt, A.; Olofsson, T.; Eriksson, P.E. Improving construction supply chain collaboration and performance: A lean construction pilot project. Supply Chain Manag. Int. J. 2010, 15, 394-403. [CrossRef]

7. Naoum, S. An overview into the concept of partnering. Int. J. Proj. Manag. 2003, 21, 71-76. [CrossRef] 
8. Bresnen, M. Deconstructing partnering in project-based organisation: Seven pillars, seven paradoxes and seven deadly sins: European Academy of Management (EURAM 2006) Conference. Int. J. Proj. Manag. 2007, 25, 365-374. [CrossRef]

9. Larsson, J.; Lasson, L. Integration, Application and Importance of Collaboration in Sustainable Project Management. Sustainability 2020, 12, 585. [CrossRef]

10. Chan, D.W.M.; Chan, A.P.C.; Lam, P.T.I.; Wong, J.M.W. An empirical survey of the motives and benefits of adopting guaranteed maximum price and target cost contracts in construction. Int. J. Proj. Manag. 2011, 29, 577-590. [CrossRef]

11. Suprapto, M.; Bakker, H.L.M.; Mooi, H.G.; Hertogh, M.J.C.M. How do contract types and incentives matter to project performance? Int. J. Proj. Manag. 2016, 34, 1071-1087. [CrossRef]

12. Bresnen, M.; Marshall, N. Building partnerships: Case studies of client contractor collaboration in the UK construction industry. Constr. Manag. Econ. 2000, 18, 819-832. [CrossRef]

13. Yang, Y.; Tang, W.; Shen, W.; Wang, T. Enhancing Risk Management by Partnering in International EPC Projects: Perspective from Evolutionary Game in Chinese Construction Companies. Sustainability 2019, 11, 5332. [CrossRef]

14. Hodge, G.; Greve, C. Public-Private Partnerships: Governance Scheme or Language Game? Aust. J. Public Adm. 2010, 69, S8-S22. [CrossRef]

15. Baxter, D.; Casady, C.B. Proactive and Strategic Healthcare Public-Private Partnerships (PPPs) in the Coronavirus (Covid-19) Epoch. Sustainability 2020, 12, 5097. [CrossRef]

16. Matinheikki, J.; Aaltonen, K.; Walker, D. Politics, public servants, and profits: Institutional complexity and temporary hybridization in a public infrastructure alliance project. Int. J. Proj. Manag. 2019, 37, 298-317. [CrossRef]

17. Walker, D.H.T. Collaborative Project Procurement Arrangements; Project Management Institute, Inc.: Newtown Square, PA, USA, 2015; ISBN 978-1-62825-094-7.

18. Macneil, I.R. Reflections on Relational Contract. J. Inst. Theor. Econ. 1985, 141, 541-546.

19. Lahdenperä, P. Making sense of the multi-party contractual arrangements of project partnering, project alliancing and integrated project delivery. Constr. Manag. Econ. 2012, 30, 57-79. [CrossRef]

20. Larson, E. Project Partnering: Results of Study of 280 Construction Projects. J. Manag. Eng. 1995, 11, 30. [CrossRef]

21. Manu, E.; Ankrah, N.; Chinyio, E.; Proverbs, D. Trust influencing factors in main contractor and subcontractor relationships during projects. Int. J. Proj. Manag. 2015, 33, 1495-1508. [CrossRef]

22. Jashapara, A.; Barlow, J.; Cohen, M.; Simpson, Y. Towards Positive Partnering; The Policy Press: Bristol, UK, 1997.

23. Wright, J.N.; Fergusson, W. Benefits of the NEC ECC form of contract: A New Zealand case study. Int. J. Proj. Manag. 2009, 27, 243-249. [CrossRef]

24. Bygballe, L.E.; Jahre, M.; Swärd, A. Partnering relationships in construction: A literature review. J. Purch. Supply Manag. 2010, 16, 239-253. [CrossRef]

25. Merrow, E.W. Industrial Megaprojects Concepts, Strategies, and Practices for Success; Wiley: Hoboken, NJ, USA, 2011; ISBN 978-161344-518-1.

26. Alderman, N.; Ivory, C. Partnering in major contracts: Paradox and metaphor: European Academy of Management (EURAM 2006) Conference. Int. J. Proj. Manag. 2007, 25, 386-393. [CrossRef]

27. Wang, N.; Ma, M.; Liu, Y. The Whole Lifecycle Management Efficiency of the Public Sector in PPP Infrastructure Projects. Sustainability 2020, 12, 3049. [CrossRef]

28. Eriksson, P.E. Partnering in engineering projects: Four dimensions of supply chain integration. J. Purch. Supply Manag. 2015, 21, 38-50. [CrossRef]

29. Chan, A.P.C.; Chan, D.W.M.; Fan, L.C.N.; Lam, P.T.I.; Yeung, J.F.Y. Partnering for construction excellence-A reality or myth? Build. Environ. 2006, 41, 1924-1933. [CrossRef]

30. Xue, X.; Shen, Q.; Ren, Z. Critical Review of Collaborative Working in Construction Projects: Business Environment and Human Behaviors. J. Manag. Eng. 2010, 26, 196-208. [CrossRef]

31. Daniel, E.; Daniel, P.A. Megaprojects as complex adaptive systems: The Hinkley point C case. Int. J. Proj. Manag. 2019, 37, 1017-1033. [CrossRef]

32. Qiu, Y.; Chen, H.; Sheng, Z.; Cheng, S. Governance of institutional complexity in megaproject organizations. Int. J. Proj. Manag. 2019, 37, 425-443. [CrossRef]

33. GAPPS. A Framework for Performance Based Competency Standards for Global Level 1 and 2 Project Managers; Global Alliance for Project Performance Standards: Johannesburg, South Africa, 2007.

34. Bosch-Rekveldt, M.G.C. Managing Project Complexity: A Study into Adapting Early Project Phases to Improve Project Performance in Large Engineering Projects. Ph.D. Thesis, Technical University of Delft, The Hague, The Netherlands, 2011.

35. Bakhshi, J.; Ireland, V.; Gorod, A. Clarifying the project complexity construct: Past, present and future. Int. J. Proj. Manag. 2016, 34, 1199-1213. [CrossRef]

36. Rolstadås, A.; Schiefloe, P.M. Modelling project complexity. Int. J. Manag. Proj. Bus. 2017, 10, 295-314. [CrossRef]

37. Maylor, H.; Vidgen, R.; Carver, S. Managerial Complexity in Project-Based Operations: A Grounded Model and Its Implications for Practice. Proj. Manag. J. 2008, 39, S15-S26. [CrossRef]

38. Kermanshachi, S.; Dao, B.; Rouhanizadeh, B.; Shane, J.; Anderson, S. Development of the Project Complexity Assessment and Management Framework for Heavy Industrial Projects. Int. J. Constr. Educ. Res. 2020, 16, 24-42. [CrossRef]

39. Williams, T.M. The Nature of Risk in Complex Projects. Proj. Manag. J. 2017, 48, 55-66. [CrossRef] 
40. Bosch-Rekveldt, M.; Jongkind, Y.; Mooi, H.; Bakker, H.; Verbraeck, A. Grasping project complexity in large engineering projects: The TOE (Technical, Organizational and Environmental) framework. Int. J. Proj. Manag. 2011, 29, 728-739. [CrossRef]

41. Crawford, L.H.; Pollack, J.B. Developing a Basis for Global Reciprocity: Negotiating Between the Many Standards for Project Management. Int. J. IT Stand. Stand. Res. 2008, 6, 70-84. [CrossRef]

42. Aitken, A.; Crawford, L.H. A Study of Project Categorisation Based on Project Management Complexity. In Proceedings of the IRNOP VIII Conference, Brighton, UK, 19-21 September 2007; University of Sussex: Brighton, UK, 2007.

43. NSW Government. NSW Government Action Plan | A Ten Point Commitment to the Construction Secctor; Sydney, 2018. Available online: http:/ / www.infrastructure.nsw.gov.au/media/1649/10-point-commitment-to-the-construction-industry-final-002.pdf (accessed on 18 February 2020).

44. Hosseini, A.; Knotten, V.; Klakegg, O.J. «Next step»: A new Systematic Approach to Plan and Execute AEC Projects. In WBC16 CIB World Building Congress 2016, 1-3 June 2016; Saari, A., Huovinen, P., Eds.; Tampere University of Technology: Tampere, Finland, 2016; Volume III, pp. 484-495.

45. Martinsuo, M.; Klakegg, O.J.; van Marrewijk, A. Editorial: Delivering value in projects and project-based business. Int. J. Proj. Manag. 2019, 37, 631-635. [CrossRef]

46. Klakegg, O.J. In Pursuit of Relevance and Sustainability. Open Econ. Manag. J. 2015, 2. [CrossRef]

47. Aarhaug, J.; Fearnley, N.; Gregersen, F.A.; Norseng, R.B. 20 years of competitive tendering in the Norwegian bus industry-An analysis of bidders and winning bids. Res. Transp. Econ. 2018, 69, 97-105. [CrossRef]

48. Schmidt, K.M. Contributions of Oliver Hart and Bengt Holmström to Contract Theory. Scand. J. Econ. 2017, 119, 489-511. [CrossRef]

49. Williams, T.; Samset, K. Issues in Front-End Decision Making on Projects. Proj. Manag. J. 2010, 41, 38-49. [CrossRef]

50. Williams, T. Identifying Success Factors in Construction Projects: A Case Study. Proj. Manag. J. 2016, 47, 97-112. [CrossRef]

51. Snowden, D.J.; Boone, M.E. A Leader's Framework for Decision Making. (cover story). Harv. Bus. Rev. 2007, 85, 68-76. 